\title{
Alcohol consumption and the risk of incident atrial fibrillation among people with cardiovascular disease
}

\author{
Yan Liang MD, Andrew Mente PhD, Salim Yusuf MB DPhil, Peggy Gao MSc, Peter Sleight MD, Jun Zhu MD, \\ Robert Fagard MD, Eva Lonn MD, Koon K. Teo MB PhD; for the ONTARGET and TRANSCEND Investigators
}

\begin{abstract}
Background: Moderate alcohol consumption may reduce cardiovascular events, but little is known about its effect on atrial fibrillation in people at high risk of such events. We examined the association between moderate alcohol consumption and the risk of incident atrial fibrillation among older adults with existing cardiovascular disease or diabetes.
\end{abstract}

Methods: We analyzed data for 30433 adults who participated in 2 large antihypertensive drug treatment trials and who had no atrial fibrillation at baseline. The patients were 55 years or older and had a history of cardiovascular disease or diabetes with end-organ damage. We classified levels of alcohol consumption according to median cut-off values for low, moderate and high intake based on guidelines used in various countries, and we defined binge drinking as more than 5 drinks a day. The primary outcome measure was incident atrial fibrillation.

Results: A total of 2093 patients had incident atrial fibrillation. The age- and sex-standardized incidence rate per 1000 person-years was 14.5 among those with a low level of alcohol consumption, 17.3 among those with a moderate level and 20.8 among those with a high level. Compared with participants who had a low level of consumption, those with higher levels had an increased risk of incident atrial fibrillation (adjusted hazard ratio [HR] 1.14, 95\% confidence interval $[\mathrm{Cl}]$ 1.04-1.26, for moderate consumption; $1.32,95 \% \mathrm{Cl} 0.97-1.80$, for high consumption). Results were similar after we excluded binge drinkers. Among those with moderate alcohol consumption, binge drinkers had an increased risk of atrial fibrillation compared with non-binge drinkers (adjusted HR $1.29,95 \% \mathrm{Cl} 1.02-1.62$ ).

Interpretation: Moderate to high alcohol intake was associated with an increased incidence of atrial fibrillation among people aged 55 or older with cardiovascular disease or diabetes. Among moderate drinkers, the effect of binge drinking on the risk of atrial fibrillation was similar to that of habitual heavy drinking.
A trial fibrillation is associated with an increased risk of stroke and a related high burden of mortality and morbidity, both in the general public and among patients with existing cardiovascular disease. ${ }^{1,2}$ The prevalence of atrial fibrillation increases steadily with age, as do the associated risks, and atrial fibrillation accounts for up to $23.5 \%$ of all strokes among elderly people. ${ }^{3}$

Moderate alcohol consumption has been reported to be associated with a reduced risk of cardiovascular disease and all-cause death, ${ }^{1,2}$ whereas heavy alcohol intake and binge drinking have been associated with an increased risk of stroke,${ }^{4}$ cardiovascular disease and all-cause death. ${ }^{5,6}$ Similarly, heavy drinking and binge drinking are associated with an increased risk of incident atrial fibrillation in the general population. ${ }^{7}$ However, the association between moderate drinking and incident atrial fibrillation is less consistent and not well understood among older people with existing cardiovascular disease.

In this analysis, we examined whether drinking moderate quantities of alcohol, and binge drinking, would be associated with an increased risk of incident atrial fibrillation in a large cohort of people with existing cardiovascular disease or diabetes with end-organ damage who had been followed prospectively in 2 long-term antihypertensive drug treatment trials.

\section{Methods}

\section{Study participants}

We included participants in the ONTARGET (Ongoing Telmisartan Alone and in Combination with Ramipril Global Endpoint Trial) and TRANSCEND (Telmisartan Randomised Assessment Study in ACE Intolerant Subjects with Cardiovascular Disease) trials, ${ }^{8,9}$ two paral-
Competing interests: Salim Yusuf, Peter Sleight, Robert Fagard, Eva Lonn and Koon Teo received consulting and speaker fees and research grants from Boehringer Ingelheim during the conduct of the ONTARGET and TRANSCEND trials. No competing interests declared by Yan Liang, Andrew Mente, Peggy Gao and Jun Zhu.

This article has been peer reviewed.

Correspondence to: Yan Liang, fwliangyan@yahoo .com.cn

CMAJ 2012. DOI:10.1503 /cmaj.120412 
lel, randomized controlled, double-blind trials that followed a common protocol. The ONTARGET trial compared the effects of the combination of telmisartan plus ramipril with telmisartan or ramipril alone daily in 25620 patients. The TRANSCEND trial enrolled 5926 participants who were intolerant to angiotensin-convertingenzyme (ACE) inhibitors and compared telmisartan treatment with placebo.

In both trials, patients were included if they were free of heart failure and were at high risk of cardiovascular events (age $\geq 55$ years plus a history of either cardiovascular disease [e.g., coronary artery disease, peripheral artery disease and cerebrovascular disease] or diabetes mellitus with end-organ damage). For both trials, participants were recruited from 733 collaborating centres in 40 countries between November 2001 and May 2004 and were followed at 6-month intervals for a median of 56 months. Approval was obtained from the institutional ethics committee of each centre, and all participants provided written informed consent. ${ }^{89}$

\section{Assessment of alcohol consumption}

Alcohol intake was assessed by questionnaire during a baseline clinical visit. Participants were asked for information on whether they regularly consumed alcohol, the number of drinks per week, the number of days per month during which they consumed alcohol and whether they had consumed more than 5 drinks per day.

Regular alcohol consumption was defined as at least 1 drink per week of a standard glass of beer $(355 \mathrm{~mL})$, wine $(150 \mathrm{~mL})$ or shot of hard liquor $(45 \mathrm{~mL})$. We used median cut-off values based on guidelines used in various countries on daily alcohol intake to classify participants' level of consumption as low ( $<1$ drink/week, reference category), moderate (up to 2 drinks/day [114 drinks/week] for women and up to 3 drinks/day [1-21 drinks/week] for men) and high ( $>2$ drinks/day for women and $>3$ drinks/day for men). ${ }^{10}$ Binge drinking was defined as having more than 5 drinks per day at any one time or a calculated average ingestion of more than 5 drinks per day. The group of binge drinkers was a subgroup of the moderate- and high-intake categories and therefore not mutually exclusive of these groups.

\section{Outcome measures}

The primary composite outcome of the main study, published elsewhere, was death from cardiovascular causes, myocardial infarction, stroke or hospital admission because of heart failure. ${ }^{8}$ The primary outcome of our analysis was incident atrial fibrillation, which was determined by the site investigators who completed specific questions and event forms on the presence of atrial fibrillation and related conditions at each follow-up visit. Electrocardiograms (ECGs) were required when atrial fibrillation was detected. They were also obtained for all participants at baseline, at 2 years and at the penultimate follow-up visit. Diagnosis of new-onset atrial fibrillation and event dates were made by the site investigators based on the ECGs showing atrial fibrillation; we compiled information for our study from the event forms and follow-up forms completed at each visit.

\section{Statistical analysis}

Since the entry criteria and study conduct were similar between the 2 trials, other than ACE inhibitor intolerance in the TRANSCEND trial, we pooled the data from both studies in our analysis. We included data for all of the participants in the 2 trials who had no atrial fibrillation at baseline. Percentages of participants with incident atrial fibrillation and incidence rates per 1000 person-years were obtained. We adjusted standardized incidence rates across alcohol consumption groups for age and sex using the direct standardization approach, with the ONTARGET and TRANSCEND populations as the standard. ${ }^{11}$

We used multivariable Cox regression models to test the associations with different levels of alcohol consumption and calculated the hazard ratios (HRs) with 95\% confidential intervals (CIs) for atrial fibrillation, based on the time to occurrence of first event. We created 4 adjustment models to calculate HRs using factors that were significant $(p<0.05)$ in the univariable analysis as well as other risk factors reported in the literature.

To examine the possibility of competing risks of the effect of alcohol intake on death and the effect on the risk of atrial fibrillation, we used a proportional hazards model developed by Fine and Gray. ${ }^{12}$ This competing risk regression model considers the effect of alcohol intake on the subhazard function, accounting for the competing risk of all-cause death. We performed subgroup analyses for key characteristics that might modify the association between alcohol intake and atrial fibrillation. Statistical interaction was tested using the Wald test.

We used the statistical software SAS version 8.2 for Unix (SAS Institute Inc, Cary, NC) for all analyses except for the competing risk regression, for which we used the statistical software $\mathrm{R}$, cmprsk package (version 2.2-2, www.rproject.org). A 2-tailed $p$ value of less than 0.05 was considered statistically significant. 


\section{Results}

Of the 31546 patients enrolled in the 2 trials, we excluded $61(0.2 \%)$ because of a lack of relevant information about their alcohol consumption and 1052 (3.3\%) because they had evidence of atrial fibrillation at baseline, which left 30433 for our analysis. The mean age of the patients was $66.4 \pm 7.2$ years, and 9064
(29.8\%) were women. The baseline characteristics are shown in Table 1. Overall, 18775 (61.7\%) of the patients had a low level of alcohol consumption, 11139 (36.6\%) were moderate drinkers, and $519(1.7 \%)$ had a high level of consumption. Binge drinking was identified in 1204 participants $(4.0 \%)$ and was more prevalent among men than among women $(5.2 \% \mathrm{v}$. $0.9 \%$ ) (Table 2). Most of the binge drinkers

\section{Table 1: Baseline characteristics of 30433 patients who had existing cardiovascular disease or diabetes} with end-organ damage, by level of alcohol consumption*

\begin{tabular}{|c|c|c|c|c|}
\hline \multirow[b]{2}{*}{ Characteristic } & \multicolumn{4}{|c|}{ Level of alcohol consumption; no. (\%) of patients† } \\
\hline & $\begin{array}{c}\text { All } \\
n=30433\end{array}$ & $\begin{array}{c}\text { Low } \\
n=18775\end{array}$ & $\begin{array}{l}\text { Moderate } \\
n=11139\end{array}$ & $\begin{array}{c}\text { High } \\
n=519\end{array}$ \\
\hline Age, $y r$, mean $\pm S D$ & $66.4 \pm 7.2$ & $66.6 \pm 7.2$ & $66.1 \pm 7.1$ & $65.2 \pm 6.7$ \\
\hline Sex, female & $9064(29.8)$ & $7464(39.8)$ & $1546(13.9)$ & $54(10.4)$ \\
\hline \multicolumn{5}{|l|}{ Region } \\
\hline Americas & $9288(30.5)$ & $6051(32.2)$ & $3156(28.3)$ & $81(15.6)$ \\
\hline Europe & $14980(49.2)$ & $8400(44.7)$ & $6275(56.3)$ & $305(58.8)$ \\
\hline Australia/Asia & $6165(20.3)$ & $4324(23.0)$ & $1708(15.3)$ & $133(25.6)$ \\
\hline Waist:hip ratio, mean \pm SD & $0.94 \pm 0.08$ & $0.93 \pm 0.09$ & $0.95 \pm 0.08$ & $0.96 \pm 0.07$ \\
\hline \multicolumn{5}{|l|}{ Medical history } \\
\hline Coronary artery disease & $23422(77.0)$ & $14001(74.6)$ & $9023(81.0)$ & $398(76.7)$ \\
\hline Stroke/TIA & $6261(20.6)$ & $4128(22.0)$ & $2019(18.1)$ & $114(22.0)$ \\
\hline Peripheral artery disease & 5439 (17.9) & $3176(16.9)$ & $2118(19.0)$ & 145 (27.9) \\
\hline Hypertension & $21315(70.0)$ & $13938(74.2)$ & $7076(63.5)$ & $301(58.0)$ \\
\hline Diabetes & $11345(37.3)$ & $8005(42.6)$ & $3218(28.9)$ & $122(23.5)$ \\
\hline Chronic renal disease & $8178(26.9)$ & $5475(29.2)$ & $2587(23.2)$ & $116(22.4)$ \\
\hline Sleep apnea & $2033 \quad(6.7)$ & $1313(7.0)$ & $697 \quad(6.3)$ & $23(4.4)$ \\
\hline Use of statin & $18503(60.8)$ & $10619(56.6)$ & $7519(67.5)$ & $365(70.3)$ \\
\hline \multicolumn{5}{|l|}{ Smoking status } \\
\hline Never smoked & $11418(37.5)$ & $8624(45.9)$ & $2747(24.7)$ & $47 \quad(9.1)$ \\
\hline Current/former smoker & $18983(62.4)$ & $10132(54.0)$ & $8381(75.2)$ & $470(90.6)$ \\
\hline \multicolumn{5}{|l|}{ Education } \\
\hline None & 1115 (3.7) & $977 \quad(5.2)$ & $131 \quad(1.2)$ & 7 (1.3) \\
\hline $1-8 \mathrm{yr}$ & $9120(30.0)$ & $6302(33.6)$ & $2677(24.0)$ & $141(27.2)$ \\
\hline $9-12 \mathrm{yr}$ & $8987(29.5)$ & $5422(28.9)$ & $3405(30.6)$ & $160(30.8)$ \\
\hline University/trade school & $11204(36.8)$ & $6072(32.3)$ & $4921(44.2)$ & $211(40.7)$ \\
\hline \multicolumn{5}{|l|}{ Physical activity } \\
\hline Sedentary & 10486 (34.5) & $7101(37.8)$ & $3200(28.7)$ & $185(35.6)$ \\
\hline Moderate & 6971 (22.9) & $3903(20.8)$ & $2951(26.5)$ & $117(22.5)$ \\
\hline High & 12966 (42.6) & 7766 (41.4) & $4983(44.7)$ & $217(41.8)$ \\
\hline \multicolumn{5}{|l|}{ Stress§ } \\
\hline Yes & $19685(64.7)$ & $12156(64.7)$ & $7210(64.7)$ & $319(61.5)$ \\
\hline No & $10734(35.3)$ & $6612(35.2)$ & $3923(35.2)$ & $199(38.3)$ \\
\hline \multicolumn{5}{|c|}{ 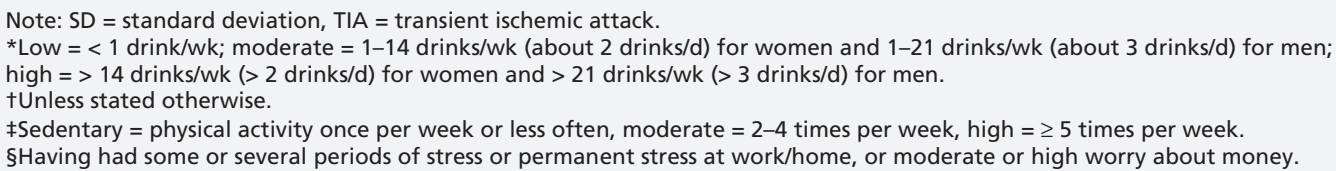 } \\
\hline
\end{tabular}


(78.7\% [948/1204]) were in the group of moderate alcohol consumption (Table 3 ).

\section{Incidence of atrial fibrillation}

During follow-up, there were 2093 cases of incident atrial fibrillation. Of these, $1507(72.0 \%)$ were clinically apparent episodes, and 586 $(28.0 \%)$ were asymptomatic and were detected on routine ECGs obtained at 2 years or at the penultimate follow-up visit. A few were detected by ECGs recorded for other reasons. The incidence rate per 1000 person-years was 14.2 in the group with a low level of alcohol consumption, 17.5 in the group of moderate drinkers and 18.7 in the group with a high level of consumption (Table 4). The incidence rates increased with

Table 2: Baseline characteristics of patients, by binge-drinking status*

\begin{tabular}{|c|c|c|c|}
\hline \multirow[b]{2}{*}{ Characteristic } & \multirow{2}{*}{$\begin{array}{c}\text { Low alcohol } \\
\text { consumption, no. }(\%) \dagger \\
n=18775\end{array}$} & \multicolumn{2}{|c|}{$\begin{array}{c}\text { Moderate or high alcohol consumption, } \\
\text { no. (\%) of patientst }\end{array}$} \\
\hline & & $\begin{array}{c}\text { No binge drinking } \\
n=10454\end{array}$ & $\begin{array}{l}\text { Binge drinking } \\
n=1204\end{array}$ \\
\hline Age, yr, mean $\pm S D$ & $66.6 \pm 7.2$ & $66.3 \pm 7.1$ & $64.2 \pm 6.7$ \\
\hline Sex, female & 7464 (39.8) & $1515(14.5)$ & $85(7.1)$ \\
\hline \multicolumn{4}{|l|}{ Region } \\
\hline Americas & $6051(32.2)$ & $2947(28.2)$ & $290(24.1)$ \\
\hline Europe & $8400(44.7)$ & $5904(56.5)$ & $676(56.1)$ \\
\hline Australia/Asia & $4324(23.0)$ & $1603(15.3)$ & $238(19.8)$ \\
\hline Waist:hip ratio, mean \pm SD & $0.93 \pm 0.09$ & $0.95 \pm 0.08$ & $0.96 \pm 0.07$ \\
\hline \multicolumn{4}{|l|}{ Medical history } \\
\hline Coronary artery disease & $14001(74.6)$ & $8464(81.0)$ & $957(79.5)$ \\
\hline Stroke/TIA & $4128(22.0)$ & $1905(18.2)$ & $228(18.9)$ \\
\hline Peripheral artery disease & 3176 (16.9) & $1991(19.0)$ & $272(22.6)$ \\
\hline Hypertension & $13938(74.2)$ & $6646(63.6)$ & $731(60.7)$ \\
\hline Diabetes & $8005(42.6)$ & $2989(28.6)$ & $351(29.2)$ \\
\hline Chronic renal disease & $5475(29.2)$ & $2442(23.4)$ & $261(21.7)$ \\
\hline Sleep apnea & $1313(7.0)$ & $637 \quad(6.1)$ & $83(6.9)$ \\
\hline Use of statin & $10619(56.6)$ & $7053(67.5)$ & $831(69.0)$ \\
\hline \multicolumn{4}{|l|}{ Smoking status } \\
\hline Never smoked & $8624(45.9)$ & $2582(24.7)$ & $212(17.6)$ \\
\hline Current/former smoker & $10132(54.0)$ & $7861(75.2)$ & $990(82.2)$ \\
\hline \multicolumn{4}{|l|}{ Education } \\
\hline None & $977 \quad(5.2)$ & $127 \quad(1.2)$ & $11(0.9)$ \\
\hline $1-8 \mathrm{yr}$ & 6302 (33.6) & $2541(24.3)$ & $277(23.0)$ \\
\hline $9-12 y r$ & 5422 (28.9) & $3165(30.3)$ & $400(33.2)$ \\
\hline University/trade school & $6072(32.3)$ & $4616(44.2)$ & $516(42.9)$ \\
\hline \multicolumn{4}{|l|}{ Physical activity } \\
\hline Sedentary & 7101 (37.8) & 3003 (28.7) & 382 (31.7) \\
\hline Moderate & 3903 (20.8) & $2743(26.2)$ & $325(27.0)$ \\
\hline High & 7766 (41.4) & $4703(45.0)$ & $497(41.3)$ \\
\hline \multicolumn{4}{|l|}{ Stress§ } \\
\hline Yes & $12156(64.7)$ & 6767 (64.7) & $762(63.3)$ \\
\hline No & $6612(35.2)$ & 3681 (35.2) & $441(36.6)$ \\
\hline \multicolumn{4}{|c|}{$\begin{array}{l}\text { Note: } \mathrm{SD}=\text { standard deviation, } \mathrm{TIA}=\text { transient ischemic attack. } \\
\text { *Binge drinking }=>5 \text { drinks/d at any one time or a calculated average ingestion of }>5 \mathrm{drinks} / \mathrm{d} \text {; non-binge drinking }=\geq 1 \\
\text { drink/wk but not meeting the criterion for binge drinking; low consumption }=<1 \text { drink/wk, moderate }=1-14 \text { drinks/wk (about } \\
2 \text { drinks/d) for women and } 1-21 \text { drinks/wk (about } 3 \text { drinks/d) for men; high }=>14 \text { drinks/wk }(>2 \text { drinks/d) for women and }>21 \\
\text { drinks/wk ( }>3 \text { drinks/d) for men. } \\
\text { tUnless stated otherwise. } \\
\text { ‡Sedentary = physical activity once per week or less often, moderate }=2-4 \text { times per week, high }=\geq 5 \text { times per week. } \\
\text { \$Having had some or several periods of stress or permanent stress at work/home, or moderate or high worry about money. }\end{array}$} \\
\hline
\end{tabular}


age. As shown in Figure 1, the increase in incidence with higher alcohol consumption was consistent within each age strata. The absolute increase in the age- and sex-standardized incidence compared with the low-intake group was 2.8 (95\% CI 1.4-4.2) events per 1000 personyears in the moderate-consumption group and 6.3 (95\% CI 1.7-10.9) events per 1000 personyears in the high-consumption group (Table 4 ). Among the binge drinkers, 100 (8.3\%) cases of incident atrial fibrillation were found, for a rate of 18.4 events per 1000 person-years.

\section{Association between alcohol intake and atrial fibrillation}

The results of our analysis of the influence of alcohol consumption on the risk of incident atrial fibrillation are summarized in Table 5. Consuming more alcohol was associated with a graded increase in risk of atrial fibrillation in the unadjusted model and after minimal adjustment for age, sex, body mass index and region ( $p$ for trend $<0.001)$. The same was true after further stepwise adjustments for additional risk factors, including a medical history of coronary artery disease, hypertension, stroke or transient ischemic attack, renal disease, being a former smoker, diabetes and stress (Table 5). In a sensitivity analysis in which we excluded binge drinkers, the estimates for moderate and heavy drinking remained robust (HR 1.13, 95\% CI 1.02-1.24 for moderate drinkers and $1.54,95 \%$ CI 1.03-2.29 for heavy drinkers; $p$ for trend $=0.005$ ).

We observed a significant graded increase in the risk of atrial fibrillation when we compared patients who were not binge drinkers (adjusted HR 1.13, 95\% CI 1.03-1.24) and those who were binge drinkers (adjusted HR 1.35, 95\% CI 1.10-1.67) with patients who had a low level of alcohol consumption (Table 6).

To understand better the effect of binge drinking on the risk of atrial fibrillation, we compared binge drinkers and non-binge drinkers among the moderate drinkers only, since $78.7 \%$ of binge drinkers came from this group. In this analysis, binge drinking was associated with an increased risk of atrial fibrillation (adjusted HR 1.29, 95\% CI 1.02-1.62) compared with non-binge drinking (incidence 8.6\% [82/948] v. 7.7\% [789/10 191]).

\section{Subgroup analysis}

In the subgroup analyses, increasing alcohol consumption was consistently associated with an increased risk of incident atrial fibrillation across different categories of age, sex, and those with or without hypertension or chronic renal disease (Figure 2). No significant effect modification by risk factors was found.

\section{Competing risks}

During the study, 3507 patients died: the deaths involved 2354 (12.5\%) of those in the low-, 1098 $(9.9 \%)$ of those in the moderate- and $55(10.6 \%)$ of those in the high-consumption groups. The fully adjusted HR for all-cause mortality was 0.79 (95\% CI 0.73-0.85) among the moderate

Table 3: Baseline characteristics of patients who were moderate drinkers, by binge-drinking status*

\begin{tabular}{|c|c|c|}
\hline \multirow[b]{2}{*}{ Characteristic } & \multicolumn{2}{|c|}{ No. $(\%)$ of patientst } \\
\hline & $\begin{array}{l}\text { No binge drinking } \\
\quad n=10191\end{array}$ & $\begin{array}{c}\text { Binge drinking } \\
n=948\end{array}$ \\
\hline Age, yr, mean \pm SD & $66.3 \pm 7.2$ & $64.1 \pm 6.7$ \\
\hline Sex, female & $1470(14.4)$ & 76 (8.0) \\
\hline \multicolumn{3}{|l|}{ Region } \\
\hline Americas & $2905(28.5)$ & $251(26.5)$ \\
\hline Europe & $5735(56.3)$ & $540(57.0)$ \\
\hline Australia/Asia & $1551(15.2)$ & $157(16.6)$ \\
\hline Waist:hip ratio, mean \pm SD & $0.95 \pm 0.08$ & $0.96 \pm 0.07$ \\
\hline \multicolumn{3}{|l|}{ Medical history } \\
\hline Coronary artery disease & $8267(81.1)$ & 756 (79.7) \\
\hline Stroke/TIA & $1848(18.1)$ & $171(18.0)$ \\
\hline Peripheral artery disease & $1912(18.8)$ & $206(21.7)$ \\
\hline Hypertension & $6504(63.8)$ & $572(60.3)$ \\
\hline Diabetes & $2930(28.8)$ & $288(30.4)$ \\
\hline Chronic renal disease & $2385(23.4)$ & $202(21.3)$ \\
\hline Sleep apnea & $625 \quad(6.1)$ & 72 (7.6) \\
\hline Use of statin & $6864(67.4)$ & $655(69.1)$ \\
\hline \multicolumn{3}{|l|}{ Smoking status } \\
\hline Never smoked & $2564(25.2)$ & $183(19.3)$ \\
\hline Current/former smoker & $7617(74.7)$ & $764(80.6)$ \\
\hline \multicolumn{3}{|l|}{ Education } \\
\hline None & $123(1.2)$ & $8(0.8)$ \\
\hline $1-8 \mathrm{yr}$ & 2464 (24.2) & $213(22.5)$ \\
\hline $9-12 \mathrm{yr}$ & $3084(30.3)$ & 321 (33.9) \\
\hline University/trade school & $4515(44.3)$ & $406(42.8)$ \\
\hline \multicolumn{3}{|l|}{ Physical activity $¥$} \\
\hline Sedentary & $2918(28.6)$ & $282(29.7)$ \\
\hline Moderate & $2687(26.4)$ & $264(27.8)$ \\
\hline High & $4581(45.0)$ & 402 (42.4) \\
\hline \multicolumn{3}{|l|}{ Stress§ } \\
\hline Yes & $6604(64.8)$ & 606 (63.9) \\
\hline No & 3581 (35.2) & $342(36.1)$ \\
\hline
\end{tabular}

Note: $\mathrm{SD}=$ standard deviation, $\mathrm{TIA}=$ transient ischemic attack.

*Binge drinking $=>5$ drinks/d at any one time or a calculated average intake of $>5$ drinks/d; non-binge drinking $=\geq 1$ drink/wk but not meeting the criterion for binge drinking; moderate consumption $=1-14$ drinks/wk (about 2 drinks/d) for women, and 1-21 drinks/wk (about 3 drinks/d) for men.

tUnless stated otherwise.

¥Sedentary = physical activity once per week or less often, moderate $=2-4$ times per week, high $=\geq 5$ times per week.

$\S$ Having had some or several periods of stress or permanent stress at work/home, or moderate or high worry about money. 
drinkers and 0.84 (95\% CI 0.64-1.10) among those in the high-consumption group, compared with the low-consumption group. Using the Fine and Gray regression model to examine the competing risks of the effect of alcohol on death and the effect on risk of atrial fibrillation, the adjusted HR for risk of atrial fibrillation was 1.16 (95\% CI 1.05-1.27) for the effect of moderate alcohol intake compared with low intake and 1.33 (95\% CI 0.98-1.92) for the effect of high intake compared with low intake. These results were consistent with the initial results of the Cox regression on risk of atrial fibrillation.

\section{Interpretation}

In this large cohort of older people with cardiovascular disease or diabetes with end-organ damage followed for 56 months, we found that moderate alcohol intake, as defined using median cut-off values based on guidelines used in various countries ${ }^{10}$ was associated with an increased

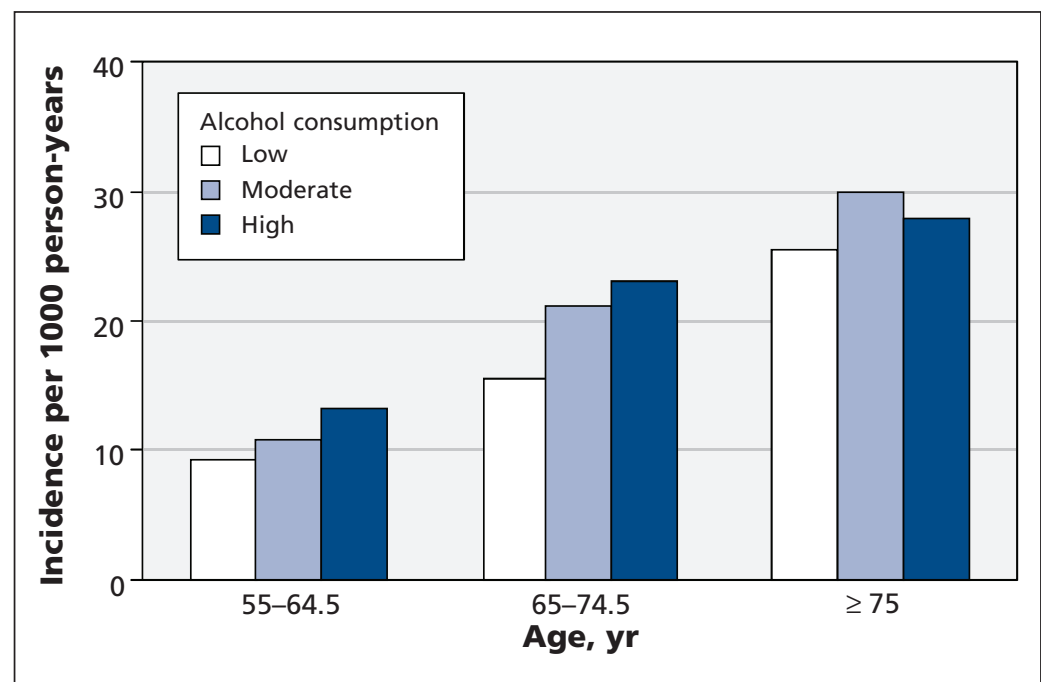

Figure 1: Incidence of atrial fibrillation per 1000 person-years among 30433 patients who had existing cardiovascular disease or diabetes with end-organ damage, by age and level of alcohol consumption. risk of atrial fibrillation. This finding remained after we adjusted for many of the potential confounders shown to be associated with incident atrial fibrillation. The magnitude of risk was strongly and significantly related to alcohol intake in a dose-response fashion irrespective of other risk factors and lifestyle. Binge drinking, even by those in the moderate-intake group, was significantly associated with an increased incidence of atrial fibrillation, with the magnitude of risk comparable to habitual heavy drinking. Subgroup analyses in our study showed a similar pattern of results across all major subgroups.

Because moderate alcohol consumption has been found to be associated with a reduced risk of cardiovascular-related outcomes, including death, ${ }^{13}$ the reduced risk of death that we observed among participants who consumed moderate levels of alcohol may allow them to survive long enough to manifest the atrial fibrillation, whereas patients at equal risk of atrial fibrillation who drink little or no alcohol may die before the atrial fibrillation reveals itself. However, when this competing risk was examined by further regression analyses, the HRs did not change materially, which suggests that the harmful effect of alcohol on atrial fibrillation persisted despite the potential for competing risks from death.

Our findings are consistent with those from most of the studies included in a meta-analysis that showed a linear relation (rather than a Jshaped or threshold curve) between alcohol consumption and risk of atrial fibrillation. ${ }^{14} \mathrm{We}$ extend these findings by providing evidence of a graded relation between alcohol intake and atrial fibrillation among high-risk patients with existing cardiovascular disease or diabetes. The incidence rates of atrial fibrillation that we observed at each level of alcohol intake in this high-risk population were several times higher than the rates reported in the general population or among patients with diabetes. ${ }^{15,16}$ The absolute increase in risk of 2.8 events per 1000 person-years associated with

Table 4: Incidence of atrial fibrillation per 1000 person-years, by level of alcohol consumption*

\begin{tabular}{|c|c|c|c|c|c|c|c|}
\hline \multirow[b]{2}{*}{$\begin{array}{l}\text { Alcohol } \\
\text { consumption }\end{array}$} & \multicolumn{2}{|c|}{ Men } & \multicolumn{2}{|c|}{ Women } & \multicolumn{3}{|c|}{ All } \\
\hline & Events, $n / N$ & Rate & Events, $n / N$ & Rate & Events, $n / N$ & Rate & $\begin{array}{c}\text { Standardized } \\
\text { rate } \dagger\end{array}$ \\
\hline Low & 761/11311 & 15.4 & $418 / 7464$ & 12.6 & 1 179/18 775 & 14.2 & 14.5 \\
\hline Moderate & 759/9 593 & 17.8 & $112 / 1546$ & 15.9 & $871 / 11139$ & 17.5 & 17.3 \\
\hline High & $38 / 465$ & 18.5 & $5 / 54$ & 20.0 & $43 / 519$ & 18.7 & 20.8 \\
\hline
\end{tabular}


moderate alcohol consumption (Table 4) was much higher than the absolute increases in risk reported in the general population. ${ }^{15,16}$

The effect of moderate alcohol consumption on incident atrial fibrillation is less clear. Our finding of an increased risk of incident atrial fibrillation associated with moderate alcohol consumption among high-risk patients is in contrast to that of several studies that found no increased risk associated with moderate alcohol consumption among people free of cardiovascular disease. ${ }^{15,17-20}$ In patients with existing cardiovascular disease, moderate alcohol consumption may incur an equal, or possibly stronger, effect on the risk of atrial fibrillation.

Because drinking moderate quantities of alcohol was common in our study $(36.6 \%$ of the participants), our findings suggest that the effect of increased alcohol consumption, even in moderate amounts, on the risk of atrial fibrillation among patients with existing cardiovascular disease may be considerable. Using Levin's formula for calculating attributable risk, ${ }^{21}$ we estimated that, for every 100 events of atrial fibrillation occurring in the population of moderate drinkers, an estimated 4.9 events $(95 \% \mathrm{CI}$ 1.4-8.7) would be prevented if every person quit drinking. This estimate is comparable to population attributable risk estimates for several other established cardiovascular risk factors..$^{22,23}$

We also examined the effect of binge drinking on the risk of atrial fibrillation in our cohort. The limited data on the association between binge drinking and atrial fibrillation among people with healthy hearts ${ }^{7}$ suggested that heavy binge drinking, as may occur on weekends or during

Table 5: Crude and adjusted hazard ratios (HRs) for incident atrial fibrillation, by level of alcohol consumption*

\begin{tabular}{|c|c|c|c|c|c|c|}
\hline \multirow[b]{2}{*}{$\begin{array}{l}\text { Alcohol } \\
\text { consumption }\end{array}$} & \multirow{2}{*}{$\begin{array}{l}\% \text { (no.) of patients } \\
\text { with incident atrial } \\
\text { fibrillation }\end{array}$} & \multicolumn{5}{|c|}{$\mathrm{HR}(95 \% \mathrm{Cl})$} \\
\hline & & $\begin{array}{l}\text { Unadjusted } \\
\text { analysis }\end{array}$ & Model 1† & Model 2‡ & Model 3§ & Model 4ף \\
\hline Low & 6.3 (1 179/18 775) & 1.00 (ref) & 1.00 (ref) & 1.00 (ref) & 1.00 (ref) & 1.00 (ref) \\
\hline Moderate & $7.8(871 / 11$ 139) & $1.23(1.12-1.34)$ & $1.15(1.05-1.26)$ & $1.16(1.06-1.28)$ & $1.14(1.04-1.26)$ & $1.14(1.04-1.26)$ \\
\hline High & $8.3(43 / 519)$ & $1.31(0.97-1.78)$ & $1.29(0.95-1.76)$ & $1.34(0.99-1.83)$ & $1.32(0.97-1.80)$ & $1.32(0.97-1.80)$ \\
\hline$p$ value for trend & & $<0.001$ & 0.001 & $<0.001$ & 0.002 & 0.002 \\
\hline \multicolumn{7}{|c|}{ 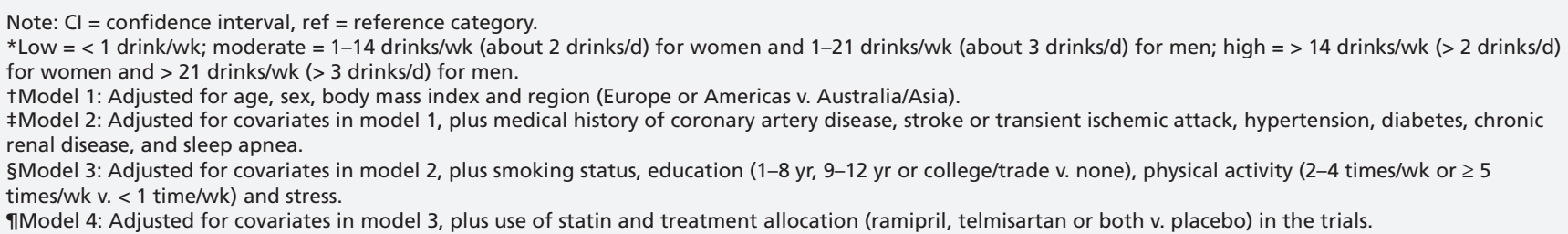 } \\
\hline
\end{tabular}

Table 6: Crude and adjusted hazard ratios (HRs) for incident atrial fibrillation, by binge-drinking status*

\begin{tabular}{|c|c|c|c|c|c|c|}
\hline \multirow[b]{2}{*}{$\begin{array}{l}\text { Alcohol } \\
\text { consumption* }\end{array}$} & \multirow{2}{*}{$\begin{array}{l}\% \text { (no.) of patients } \\
\text { with incident atrial } \\
\text { fibrillation }\end{array}$} & \multicolumn{5}{|c|}{ HR $(95 \% \mathrm{Cl})$} \\
\hline & & $\begin{array}{c}\text { Unadjusted } \\
\text { analysis }\end{array}$ & Model 1† & Model 2‡ & Model 3§ & Model 4ף \\
\hline Low & $6.3(1179 / 18$ 775) & 1.00 (ref) & 1.00 (ref) & 1.00 (ref) & 1.00 (ref) & 1.00 (ref) \\
\hline \multicolumn{7}{|l|}{ Moderate or high } \\
\hline No binge drinking & $7.8(814 / 10454)$ & $1.22(1.12-1.33)$ & $1.14(1.03-1.25)$ & $1.15(1.05-1.26)$ & $1.13(1.03-1.24)$ & $1.13(1.03-1.24)$ \\
\hline$p$ value for trend & & $<0.001$ & $<0.001$ & $<0.001$ & $<0.001$ & $<0.001$ \\
\hline \multicolumn{7}{|c|}{ 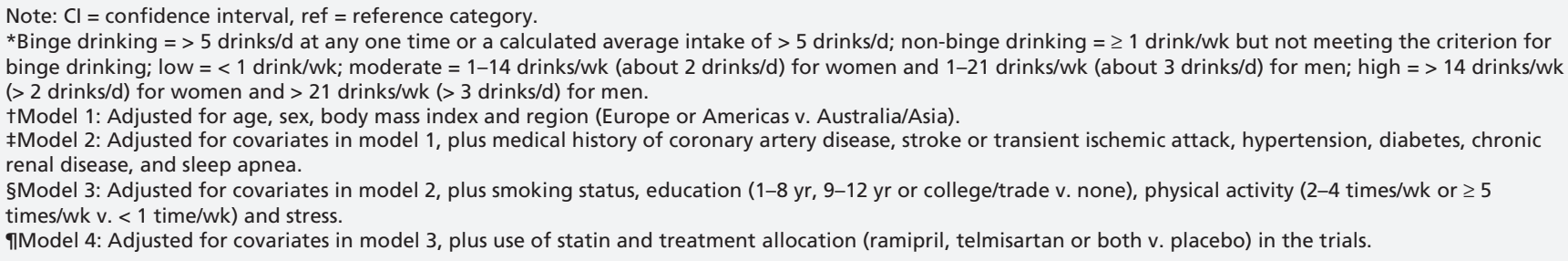 } \\
\hline
\end{tabular}


holidays ("holiday heart syndrome") may increase the risk in general, but it was unknown whether this would be the case among patients at high risk of cardiovascular events, who do not tend to indulge in heavy binge drinking. Our study showed that the occasional habit of binge drinking placed moderate drinkers at increased risk. Of note, the association between moderate alcohol consumption and atrial fibrillation risk was robust after we excluded binge drinkers from the analysis, and the dose-response relation between alcohol intake and risk of atrial fibrillation was maintained.
The underlying mechanisms linking alcohol intake to atrial fibrillation are likely multifactorial. Several experimental studies suggest associated harmful effects on maintenance of normal heart rhythm, ${ }^{14}$ including a hyperadrenergic state and impairment of vagal tone. Acute alcohol intake in healthy men has been shown to decrease heart rate variability because of diminished vagal modulation. ${ }^{24}$ Increased alcohol intake shortens the effective refractory period of the right atrium, which promotes propagation of a critically timed premature atrial complex. ${ }^{25}$ Conduction block occurs in some instances, ${ }^{26}$

\begin{tabular}{|c|c|c|c|c|}
\hline $\begin{array}{l}\text { Factor; alcohol } \\
\text { consumption }\end{array}$ & $\begin{array}{c}\text { No. of events } \\
n / N\end{array}$ & $\begin{array}{c}\text { Rate per } 1000 \\
\text { person-years }\end{array}$ & $\begin{array}{c}\text { Adjusted } \\
\mathrm{HR}^{*}(95 \% \mathrm{Cl})\end{array}$ & 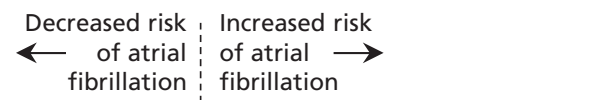 \\
\hline \multicolumn{5}{|l|}{ Overall } \\
\hline Low & 1 179/18 775 & 14.2 & 1.00 (ref) & $T$ \\
\hline Moderate & $871 / 11139$ & 17.5 & $1.14(1.04-1.26)$ & 1 \\
\hline High & $43 / 516$ & 18.7 & $1.32(0.97-1.80)$ & \\
\hline \multicolumn{5}{|l|}{ Age $\leq 65 \mathrm{yr}$} \\
\hline Low & $381 / 8838$ & 9.6 & 1.00 (ref) & 1 \\
\hline Moderate & $284 / 5493$ & 11.3 & $1.09(0.93-1.29)$ & - \\
\hline High & $19 / 284$ & 14.9 & $1.39(0.87-2.22)$ & - \\
\hline \multicolumn{5}{|l|}{ Age $>65 \mathrm{yr}$} \\
\hline Low & 798/9 937 & 18.6 & 1.00 (ref) & $\phi$ \\
\hline Moderate & $587 / 5646$ & 23.9 & $1.18(1.05-1.32)$ & $\rightarrow$ \\
\hline High & $24 / 235$ & 23.4 & $1.25(0.83-1.88)$ & \\
\hline \multicolumn{5}{|l|}{ Female } \\
\hline Low & $418 / 7464$ & 12.6 & 1.00 (ref) & \\
\hline Moderate & $112 / 1546$ & 15.9 & $1.23(0.99-1.53)$ & \\
\hline High & $5 / 54$ & 20.0 & $1.77(0.72-4.35)$ & \\
\hline \multicolumn{5}{|l|}{ Male } \\
\hline Low & 761/11 311 & 15.4 & 1.00 (ref) & $\phi$ \\
\hline Moderate & 759/9 593 & 17.8 & $1.12(1.01-1.25)$ & 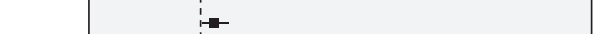 \\
\hline High & $38 / 465$ & 18.5 & $1.28(0.92-1.77)$ & \\
\hline \multicolumn{5}{|l|}{ Hypertension } \\
\hline Low & 938/13 938 & 15.4 & 1.00 (ref) & i \\
\hline Moderate & $622 / 7076$ & 19.9 & $1.15(1.03-1.29)$ & $1-$ \\
\hline High & $25 / 301$ & 18.9 & $1.20(0.80-1.80)$ & -7 \\
\hline \multicolumn{5}{|c|}{ No hypertension } \\
\hline Low & $241 / 4837$ & 11.1 & 1.00 (ref) & 中 \\
\hline Moderate & 249/4 062 & 13.5 & $1.12(0.93-1.35)$ & - \\
\hline High & $18 / 218$ & 18.4 & $1.55(0.95-2.51)$ & \\
\hline \multicolumn{5}{|l|}{ Renal disease } \\
\hline Low & $390 / 5475$ & 16.6 & 1.00 (ref) & $\dot{1}$ \\
\hline Moderate & $223 / 2587$ & 19.9 & $1.04(0.87-1.25)$ & the \\
\hline High & $14 / 116$ & 28.2 & $1.57(0.91-2.70)$ & \\
\hline \multicolumn{5}{|l|}{ No renal disease } \\
\hline Low & 789/13 300 & 13.3 & 1.00 (ref) & 中 \\
\hline Moderate & $648 / 8552$ & 16.8 & $1.19(1.06-1.33)$ & $\rightarrow$ \\
\hline High & $29 / 403$ & 16.1 & $1.22(0.84-1.77)$ & \\
\hline \multicolumn{5}{|c|}{ Current/former smoker } \\
\hline Low & $666 / 10132$ & 15.0 & 1.00 (ref) & i \\
\hline Moderate & $649 / 8381$ & 17.4 & $1.13(1.01-1.27)$ & - \\
\hline High & $41 / 470$ & 19.7 & $1.40(1.02-1.93)$ & \\
\hline \multicolumn{5}{|l|}{ Never smoked } \\
\hline Low & $513 / 8624$ & 13.4 & 1.00 (ref) & 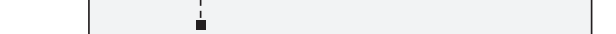 \\
\hline Moderate & $221 / 2747$ & 17.9 & $1.19(1.00-1.41)$ & - \\
\hline \multirow[t]{2}{*}{ High } & $2 / 47$ & 9.6 & $0.64(0.16-2.58)$ & $\longrightarrow$ \\
\hline & & & & 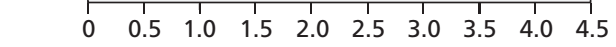 \\
\hline & & & & Adjusted HR* $(95 \% \mathrm{Cl})$ \\
\hline
\end{tabular}

Figure 2: Adjusted hazard ratios (HRs) for atrial fibrillation associated with increasing levels of alcohol consumption among patients who had existing cardiovascular disease or diabetes with end-organ damage, stratified by patient characteristics. An HR greater than 1.0 indicates an increased risk of atrial fibrillation. *Adjusted for all other factors listed. $\mathrm{Cl}=$ confidence interval, ref $=$ reference category. 
which sets up a disturbed milieu conducive to triggering atrial fibrillation. In patients with stable coronary artery disease, a moderate amount of alcohol ingestion ( $1.25 \mathrm{~g} / \mathrm{kg}$ per day) has elicited a significant decrease in vagal modulation of the heart initially, followed by a shift to sympathetic predominance and increased vasomotor activity. ${ }^{27}$ Moreover, alcohol intake leading to cardiomyopathy, increased thickening and scarring of cardiac connective tissue, altered oxidative stress, induced electrolyte imbalance and negative inotropic effect through calciumchannel inhibition in ventricular cells may also play roles in the pathogenic process.

\section{Strengths and limitations}

We examined the association between alcohol consumption and risk of atrial fibrillation in a cohort of high-risk older patients with existing cardiovascular disease or diabetes, in contrast to other studies that involved otherwise healthy individuals in the general population. Other strengths of our study are its prospective design, the large sample, the large number of events, worldwide participants, the availability of detailed covariates that could be used to adjust for a broad range of potential confounders, high completeness of systematically collected data and confirmed outcomes.

Our study had limitations. First, alcohol intake was self-reported at baseline but was not assessed during follow-up. Any changes in alcohol consumption over time would not have been captured. Second, the proportion of participants who were heavy drinkers was small, because those who were recruited and who remained in the trials were unlikely to include the heaviest drinkers. Third, recorded levels of alcohol ingestion may have been influenced by observer and respondent interpretation; however, the definition we used is commonly used in epidemiologic studies. Fourth, because ECGs were not required at each follow-up visit, episodes of asymptomatic paroxysmal atrial fibrillation may have been missed; therefore, the incidence of atrial fibrillation may be underestimated. Fifth, patients with atrial fibrillation at baseline were excluded from our analysis. Such patients may have had atrial fibrillation as a result of alcohol consumption; therefore, the association between alcohol consumption and atrial fibrillation may be underestimated. Finally, information on thyroid function was not available.

\section{Conclusion}

Moderate to high alcohol intake was associated with an increased incidence of atrial fibrillation among patients aged 55 or older with existing cardiovascular disease or diabetes. Among moderate drinkers, the effect of binge drinking on the risk of atrial fibrillation was similar to that of habitual heavy drinking. Recommendations about the protective effects of moderate alcohol intake in patients at high risk of cardiovascular disease may need to be tempered with these findings.

\section{References}

1. Beaglehole R, Jackson R. Alcohol, cardiovascular diseases and all causes of death: a review of the epidemiological evidence. Drug Alcohol Rev 1992;11:275-89.

2. Reynolds K, Lewis B, Nolen JD, et al. Alcohol consumption and risk of stroke: a meta-analysis. JAMA 2003;289:579-88.

3. Wolf PA, Abbott RD, Kannel WB. Atrial fibrillation as an independent risk factor for stroke: the Framingham Study. Stroke 1991;22:983-8.

4. Patra J, Taylor B, Irving H, et al. Alcohol consumption and the risk of morbidity and mortality for different stroke types-a systematic review and meta-analysis. BMC Public Health 2010;10:258-69.

5. Murray RP, Connett JE, Tyas SL, et al. Alcohol volume, drinking pattern, and cardiovascular disease morbidity and mortality: is there a U-shaped function? Am J Epidemiol 2002;155:242-8.

6. Makelä P, Paljärvi T, Poikolainen K. Heavy and nonheavy drinking occasions, all-cause and cardiovascular mortality and hospitalizations: a follow-up study in a population with a low consumption level. J Stud Alcohol 2005;66:722-8.

7. Thornton JR. Atrial fibrillation in healthy non-alcoholic people after an alcoholic binge. Lancet 1984;2:1013-5.

8. Yusuf S, Teo KK, Pogue J, et al.; ONTARGET Investigators. Telmisartan, ramipril, or both in patients at high risk for vascular events. N Engl J Med 2008;358:1547-59.

9. Yusuf S, Teo K, Anderson C, et al.; Telmisartan Randomised AssessmeNt Study in ACE iNtolerant subjects with cardiovascular Disease (TRANSCEND) Investigators. Effects of the angiotensinreceptor blocker telmisartan on cardiovascular events in high-risk patients intolerant to angiotensin-converting enzyme inhibitors: a randomised controlled trial. Lancet 2008;372:1174-83.

10. Department of Mental Health and Substance Dependence, Noncommunicable Diseases and Mental Health Cluster. International guide for monitoring alcohol consumption and related harm. Geneva (Switzerland): The World Health Organization; 2000. p. 54. Available: http://whqlibdoc.who.int/hq/2000/who_msd _msb_00.4.pdf (accessed 2012 Sept. 23).

11. Yusuf S, Hawken S, Ounpuu S, et al. Effect of potentially modifiable risk factors associated with myocardial infarction in 52 countries (the INTERHEART study): case-control study. Lancet 2004;364:937-52.

12. Fine JP, Gray RJ. A proportional hazards model for the subdistribution of a competing risk. J Am Stat Assoc 1999;94:496-509.

13. Ronksley PE, Brien SE, Turner BJ, et al. Association of alcohol consumption with selected cardiovascular disease outcomes: a systematic review and meta-analysis. BMJ 2011;342:d671 10.1136 /bmj.d671.

14. Kodama S, Saito K, Tanaka S, et al. Alcohol consumption and risk of atrial fibrillation: a meta-analysis. J Am Coll Cardiol 2011; 57:427-36.

15. Frost L, Vestergaard P. Alcohol and risk of atrial fibrillation or flutter: a cohort study. Arch Intern Med 2004;164:1993-8.

16. Nichols GA, Reinier K, Chugh SS. Independent contribution of diabetes to increased prevalence and incidence of atrial fibrillation. Diabetes Care 2009:32:1851-6.

17. Mukamal KJ, Tolstrup JS, Friberg J, et al. Alcohol consumption and risk of atrial fibrillation in men and women: the Copenhagen City Heart Study. Circulation 2005;112:1736-42.

18. Conen D, Tedrow UB, Cook NR, et al. Alcohol consumption and risk of incident atrial fibrillation in women. JAMA 2008; 300:2489-96.

19. Djoussé L, Levy D, Benjamin EJ, et al. Long-term alcohol consumption and the risk of atrial fibrillation in the Framingham Study. Am J Cardiol 2004;93:710-3.

20. Ruigómez A, Johansson S, Wallander MA, et al. Incidence of chronic atrial fibrillation in general practice and its treatment pattern. J Clin Epidemiol 2002;55:358-63.

21. Walter SD. The distribution of Levin's measure of attributable risk. Biometrika 1975;62:371-4

22. Schnohr P, Jensen JS, Scharling H, et al. Coronary heart disease risk factors ranked by importance for the individual and community. A 21-year follow-up of 12000 men and women from The Copenhagen City Heart Study. Eur Heart J 2002;23:620-6. 
23. Huxley RR, Lopez FL, Folsom AR, et al. Absolute and attributable risks of atrial fibrillation in relation to optimal and borderline risk factors: the Atherosclerosis Risk in Communities (ARIC) study. Circulation 2011;123:1501-8.

24. Koskinen P, Virolainen J, Kupari M. Acute alcohol intake decreases short-term heart rate variability in healthy subjects. Clin Sci 1994;87:225-30.

25. Marcus GM, Smith LM, Whiteman D, et al. Alcohol intake is significantly associated with atrial flutter in patients under 60 years of age and a shorter right atrial effective refractory period. Pacing Clin Electrophysiol 2008;31:266-72.

26. Lee KW, Yang Y, Scheinman MM. Atrial flutter: a review of its history, mechanisms, clinical features, and current therapy. Curr Probl Cardiol 2005;30:121-67.

27. Rossinen J, Viitasalo M, Partanen J, et al. Effects of acute alcohol ingestion on heart rate variability in patients with documented coronary artery disease and stable angina pectoris. Am J Cardiol 1997;79:487-91.

Affiliations: From the Population Health Research Institute (Liang, Mente, Yusuf, Gao, Lonn, Teo), Hamilton Health Sciences, McMaster University, Hamilton, Ont.; Cardiovascular Institute and Fuwai Hospital, Chinese Academy of Medical Sciences and Peking Union Medical College, Department of Emergency (Liang, Zhu), Beijing, China; the Department of Clinical Epidemiology and Biostatistics (Mente, Yusuf, Lonn, Teo), McMaster University, Hamilton, Ont.; the Department of Medicine (Yusuf, Lonn, Teo), McMaster University, Hamilton,
Ont.; John Radcliffe Hospital (Sleight), University of Oxford, UK; and Hypertension and Cardiovascular Rehabilitation Unit (Fagard), University of Leuven (KU Leuven), Leuven, Belgium

Contributors: Peter Sleight, Jun Zhu, Robert Fagard and Eva Lonn contributed to the study concept and design. Koon Teo supervised the collection of data. All of the authors contributed to the interpretation of the data. Peggy Gao performed the statistical analysis. Yan Liang drafted the manuscript. Andrew Mente, Salim Yusuf, Peggy Gao, Peter Sleight, Jun Zhu, Robert Fagard, Eva Lonn and Koon Teo revised the manuscript critically for important intellectual content. All of the authors had full access to all of the data in the study and take responsibility for the integrity of the data and the accuracy of the data analysis. All of the authors approved the final version of the manuscript submitted for publication.

Funding: The ONTARGET and TRANSCEND trials were sponsored by Boehringer Ingelheim which had no role in the study design, the collection, analysis or interpretation of data, the writing of the report or the decision to submit the article for publication.

Acknowledgement: The authors thank all of the participants, study coordinators and investigators in the ONTARGET and TRANSCEND trials for their invaluable contribution to their study. 